\title{
Punching Holes in Sheet Glass Under High Pressure*
}

\author{
Katsumi YAMAGUCHI**, Kiyoshi ISOGIMI***, \\ Eiji SHAMOTO** and Junichi KOJIMA****
}

\begin{abstract}
Many kinds of recently developed materials are very hard and brittle, and it is very difficult and expensive to process them. Thus, it is necessary to develop an easier and more economical method to process these materials. As an example, punching holes in sheet glass was studied. Because punching holes in sheet glass by ordinary methods is impossible, we present a method for punching holes in sheet glass under static high pressure. This research confirmed that it is possible to punch holes in sheet glass, and clarified the conditions needed to obtain good holes without defects.
\end{abstract}

Key Words: Manufacturing Technology, Punching, Holding Pressure, Sheet Glass, Brittle Materials

\section{Introduction}

Many kinds of recently developed materials are very hard and brittle. At present, these materials are usually processed by diamond grinding, supersonic machining and so on. These processes are rather inefficient and expensive, so a more efficient and economical method for processing these materials is required.

The objects of this research are to present a handy method for punching holes in hard and brittle sheet materials (sheet glass is used here), and to determine the necessary punching conditions. High pressure, it is presumed, has much to do with processes for brittle materials. Thus, a new method for punching under high pressure is developed.

* Received 15 th May, 1987. Paper No. 86-0070 A

** Faculty of Engineering, Nagoya University, Furocho, Chikusa-ku, Nagoya, 464, Japan

*** Faculty of Engineering, Mie University, 1515 Uehama-cho, Tsu, Mie, 514, Japan

**** Toshiba Co. Ltd., 2121 Nao, Asahi-cho, Mie-gun, Mie, 512, Japan

\section{Experimental Apparatus}

\section{1 Punching apparatus}

If sheet glass is punched with an ordinary apparatus used for punching ductile sheet metal, it will break into pieces. If it is held under extremely high pressure between a die and a holder, however, punching is presumed to be possible. In this research, in order to enable sheet glass to be punched, the following apparatus has been designed.

Figure 1 shows a sketch of the punching apparatus, and the structure is shown in Fig. 2, where (1) is a punch and (2) a die.

Before punching, sheet glass is inserted between the upper anvil (4) and the lower anvil (7) and pressed under extremely high pressure. If the nut (6) is rotated, the tapered bushing (5) is pulled inside, and as a result the punch is pushed down. The punch, the die and the anvils are made of quenched SKD 11. By exchanging the die, the punch/die clearance can be changed.

The apparatus with the dieset (shown in Fig. 1) is pressed together tightly. In order to maintain a uniform punching velocity, the nut (6) is driven by an electric motor. In this research, the velocity is about 
$0.1 \mathrm{nmm} / \mathrm{s}$

\subsection{Load and stroke defectors}

The punching process could be better understood by examining changes of the load on the punch. Both the load and the punch stroke are measured at the same time by the detectors, shown in Fig. 3 and Fig. 4. The detectors are equipped with Wheatstone bridge circuits of strain gages.

In the load detector, the strain gages are attached

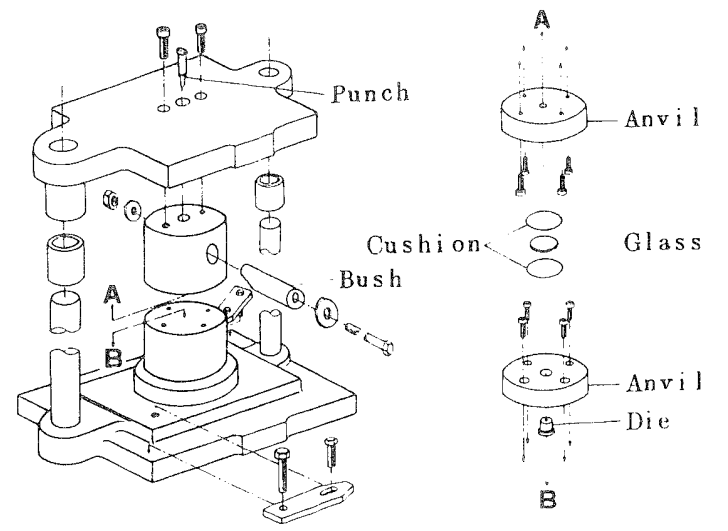

Fig. 1 Sketch of apparatus

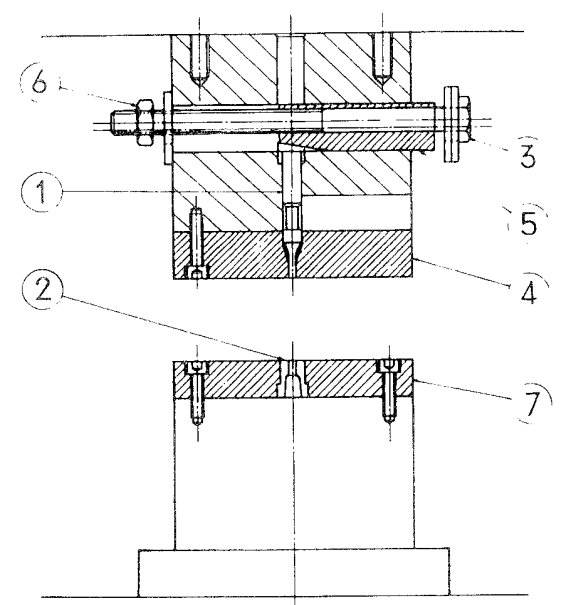

Fig. 2 Structure of apparatus

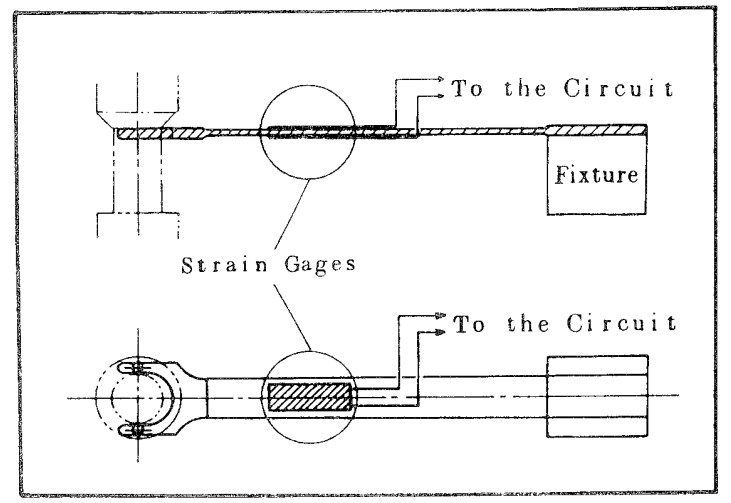

Fig. 4 Stroke detector to the constricted part of the punch as shown in Fig. 3 , and the circuit has four strain gages so as to eliminate the effects of ambient temperature and of bending moment caused by an eccentric load.

The stroke detector is equipped with strain gages both on the upper and the lower sides of a cantilever, and the head of the cantilever touches at the notch of the punch so that it may measure the punch stroke, as shown in Fig. 4.

These detectors are calibrated, and both the linearity and the reproducibility are confirmed.

\section{Cushions}

As mentioned in the preceding chapter, in this research the sheet glass is tightly pressed between the anvils while it is being punched. But as shown in Fig. 5 , the sheet glass is apt to fracture by contact with the anvils. To prevent fracture, therefore, ductile foils (named cushions) are inserted between the sheet glass and the anvils. The outline of the preliminary experiment on cushions is as follows.

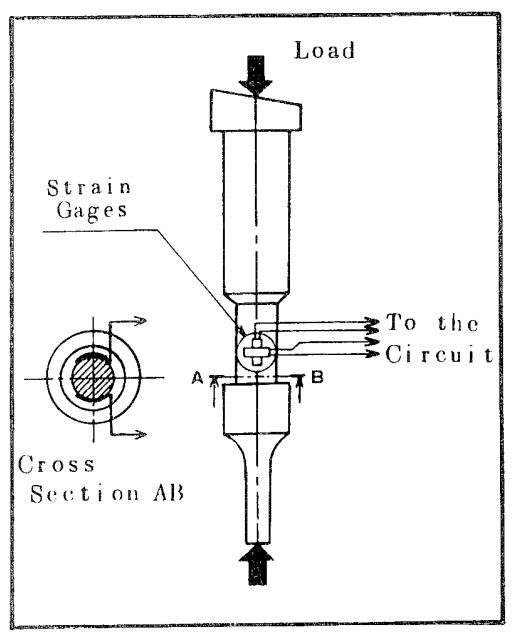

Fig. 3 Load detector

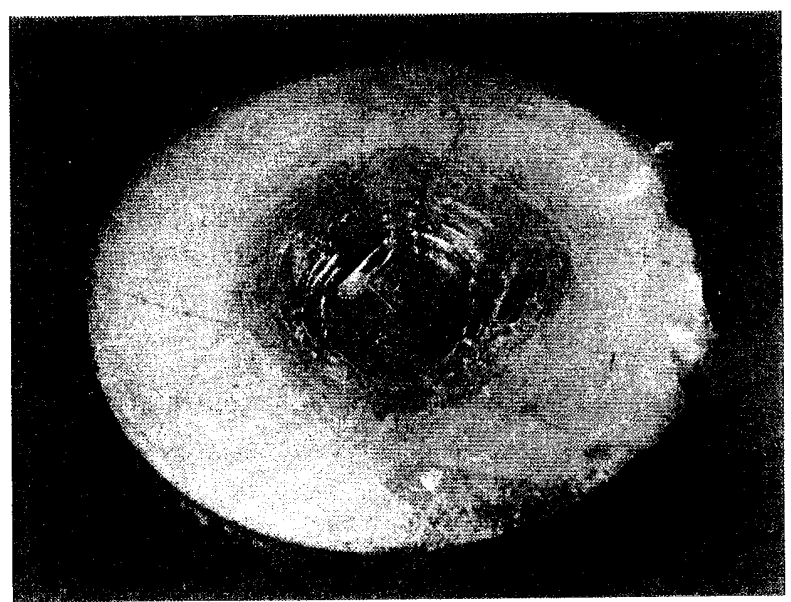

Fig. 5 Broken sheet glass 
The punching apparatus mentioned in the preceding chapter is used. The surfaces of the anvils are ground, the surface roughness $R_{\max }$ being below $3 \mu \mathrm{m}$. The blanks are commercial sheet glass, of which the surface roughness $R_{\max }$ is below $1 \mu \mathrm{m}$, the diameter 45 $\mathrm{mm}$, and the thickness $0.7 \mathrm{~mm}$.

Figure 6 shows the result obtained by pressing the sheet glass together with various cushions. The unbroken area in Fig. 6 is expressed as a percentage. It is also shown in Fig. 6 that cushions of copper foil 0.05 $\mathrm{mm}$ thick are the most suitable for the purpose, and that the unbroken area is over $80 \%$, even under the condition $p=1000 \mathrm{MPa}$, when the cushions are used. When the sheet glass is pressed without cushions, it is not broken under $400 \mathrm{MPa}$ but is shattered as soon as the pressure $p$ exceeds $400 \mathrm{MPa}$. As Fig. 6 shows, the thinner the cushions are, the larger the unbroken area is for the same cushion material. It seems that thin cushions have stronger constriction under the deformation of sheet glass.

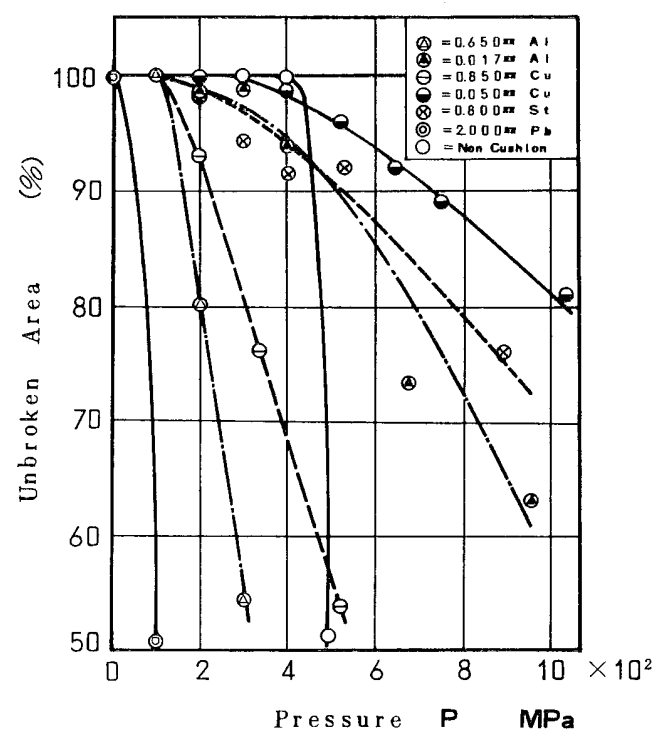

Fig. 6 Unbroken area and a variety of cushions

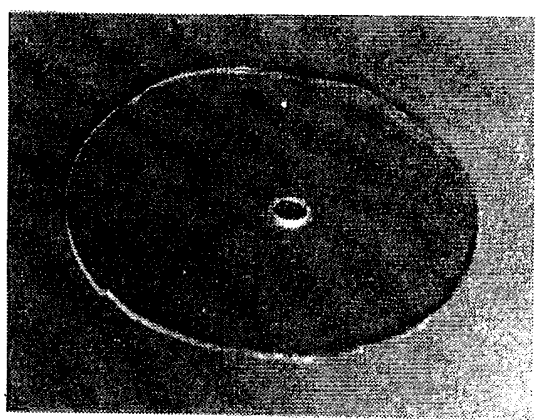

(a)

\section{Punching Experiment}

\section{1 Experimental conditions}

In accordance with the conclusion derived from the preliminary experiment, cushions of copper foil $0.05 \mathrm{~mm}$ thick are used in this research. All of the blanks used in this experiment are commercial sheet glass, with thickness $t$ ranging from $0.4 \mathrm{~mm}$ to $2.0 \mathrm{~mm}$. The blank of the sheet glass is either circular with a diameter of $45 \mathrm{~mm}$, or square with a side of $50 \mathrm{~mm}$. The punch diameter $d$ is $3 \mathrm{~mm}$, and the die diameter $d^{\prime}$ is changed within the range of $3.05 \mathrm{~mm}$ to $9.00 \mathrm{~mm}$ in order to vary the clearance. Fig. 7) :

The parameters can be summed up as follows (cf.

(1) $p$ : holding pressure on the sheet glass

(2) $c / t$ : relative clearance

( 3 ) $d / t$ : relative punch diameter

The purpose of this experiment is to elucidate the effects of these parameters on the quality of the hole.

\section{2 Formation of holes}

Figure 8 shows examples of the sheet glass punched in this research. Photo ( a ) shows an example of a hole which is punched in the center of a circular blank, while photo ( $b$ ) shows a corner of a square

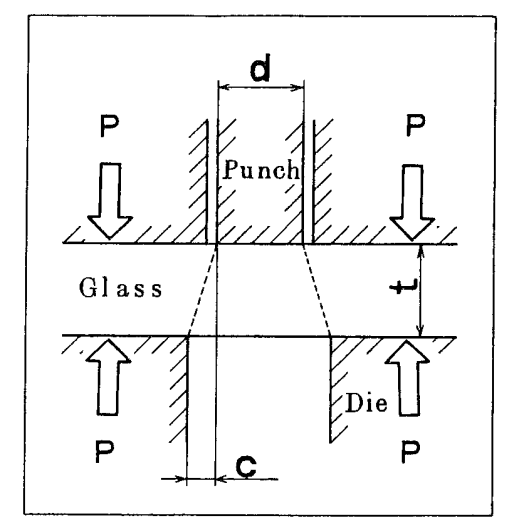

Fig. 7 Explanation of parameters

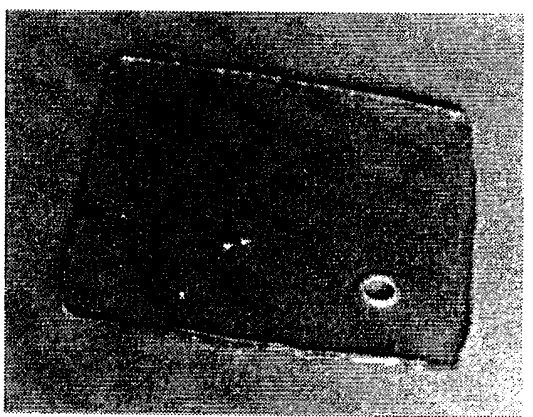

(b)

Fig. 8 Punched sheet glass 
blank.

In order to examine the propagation of cracks in sheet glass, the profiles are observed as shown in Fig. 9. The punching is supposed to be performed in the order of (a), (b), and (c) in the figure. As shown in Fig. 9, cracks are generated in the sheet glass at the edge of the punch; numerous cracks can be seen in the sheet glass, under the punch. It is emphasized that the cracks are, however, restricted within the limits of the diameter of the die and never expand to the outer held area, which is shown in Fig. 9 (c).

\section{Punching Resistance}

Oscillograms of the loads recorded during punching are shown in Fig. 10 and Fig. 11, where the punch load is defined as follows:

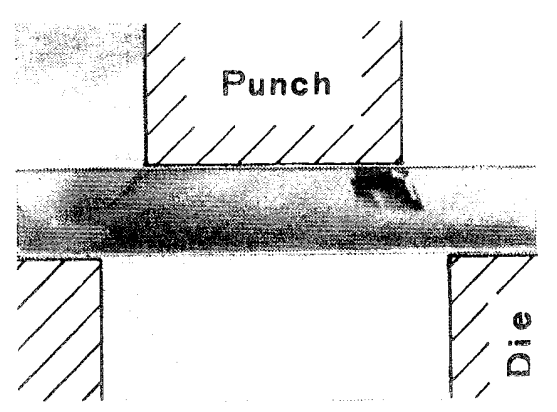

(a)

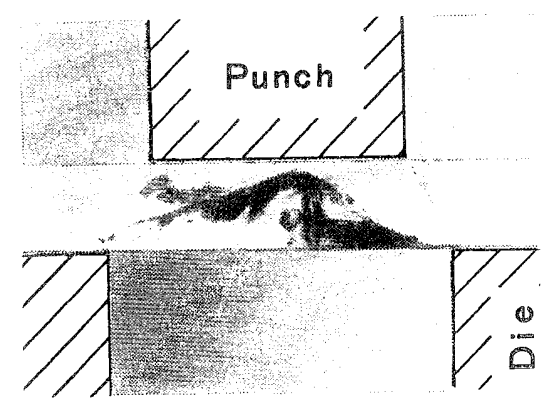

(b)

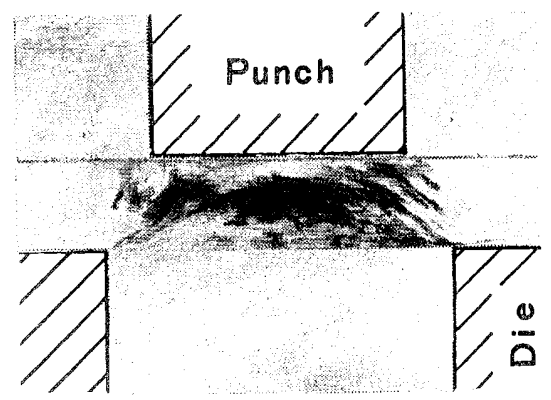

(c)

Fig. 9 Profiles at various punching stages punch load $=$

force on punch

$\pi \times($ punch diameter $d) \times($ glass thickness $t)$

Figure 10 shows how the punch loads are affected by changes in $p$, and Fig. 11, by changes in $c / t$. As shown in these figures, the punch loads increase in proportion to the stroke at an early stage, and thereafter drop abruptly. The patterns of the oscillograms are, therefore, very sharp compared with those seen in ductile materials.

The punching resistance is defined as the maxi-

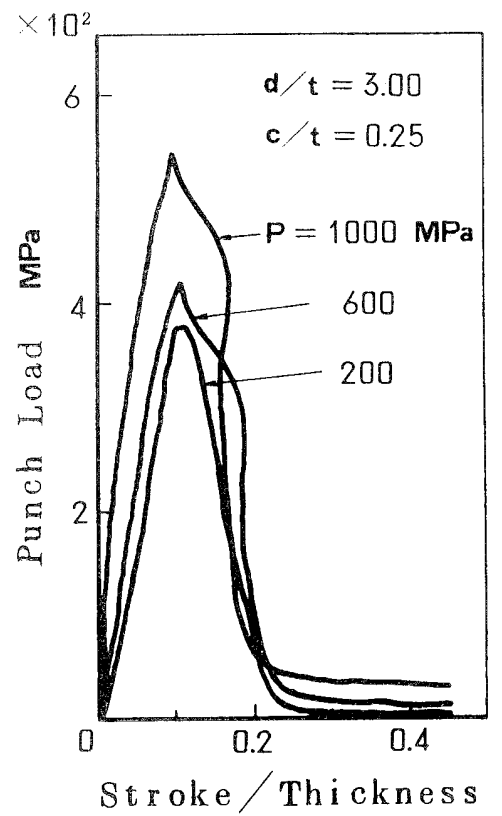

Fig. 10 Changes of punch loads by changes in $p$

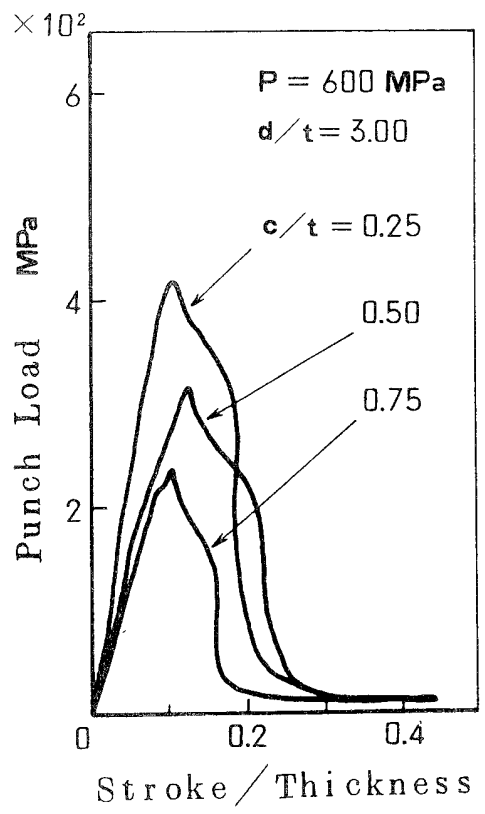

Fig. 11 Changes of punch loads by changes in $c / t$ 
mum value of the punch load in Fig. 10 and Fig. 11. The relation among this punching resistance, the pressure $p$ and the relative clearance $c / t$ is shown in Fig. 12. It shows that the punching resistance decreases with increases in $c / t$ and decreases in $p$.

The smaller the punching resistance is, the better the punching operation is. This can be realized in the case of a large clearance or low pressure. However, the increase of the relative clearance $c / t$ is liable to compromise the hole quality, and the decrease of the pressure $p$ intensifies the possibility of damage in the held area. If these disadvantages are to be avoided, the punching conditions are inevitably restricted.

\section{Evaluation of Punched Holes}

Some typical examples of punched holes are shown in Fig. 13. The hole (a) has no cracks. The hole ( $b$ ) has small circular cracks, but no radial ones. The hole (c) has small radial cracks as well as circular ones. The hole (d) has large radial cracks, too.

Punched holes can be evaluated as follows. With reference to Fig. 14, $D_{\max }$ is defined as the maximum diameter of the damaged part in the sheet glass

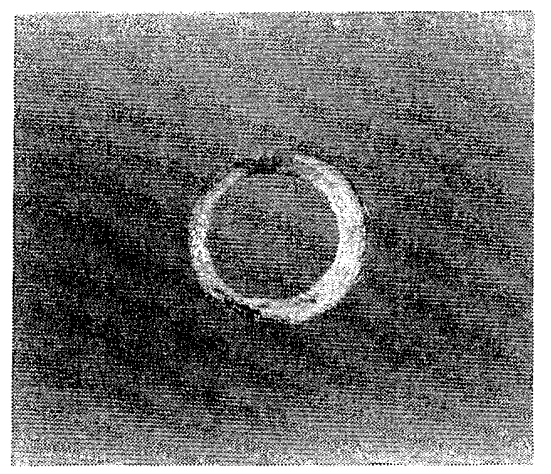

(a)

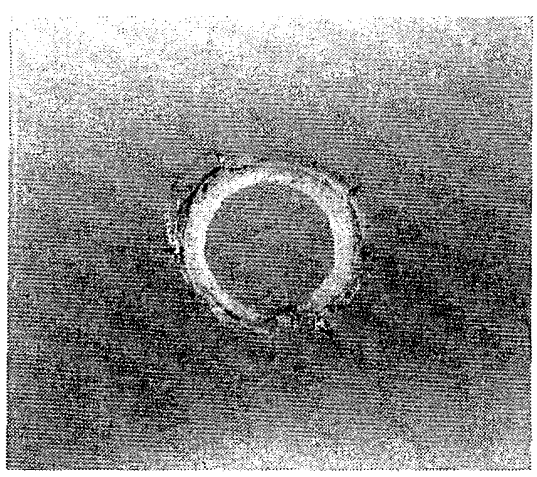

(c)

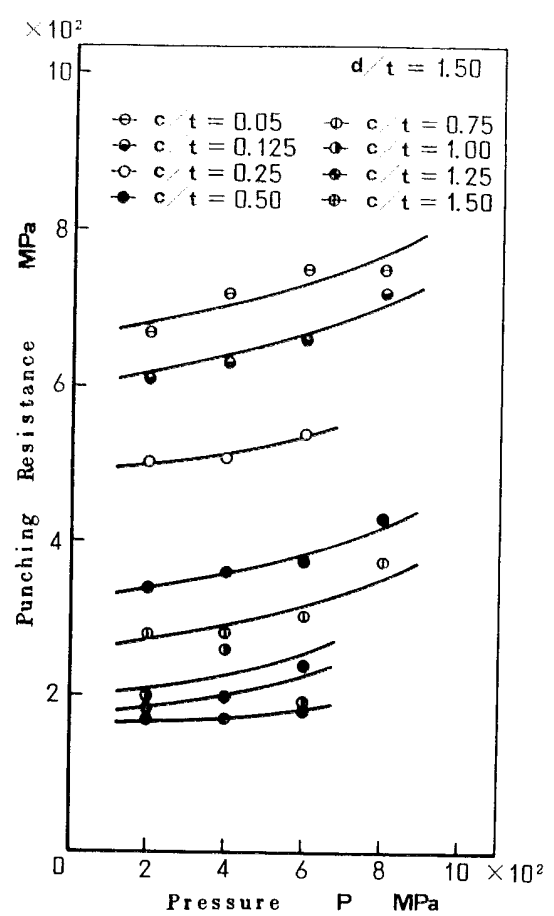

Fig. 12 Relation amang punching resistance, pressure $p$, and relative clearance $c / t$

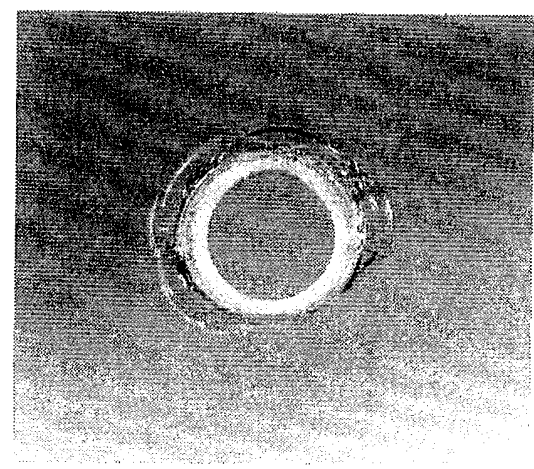

(b)

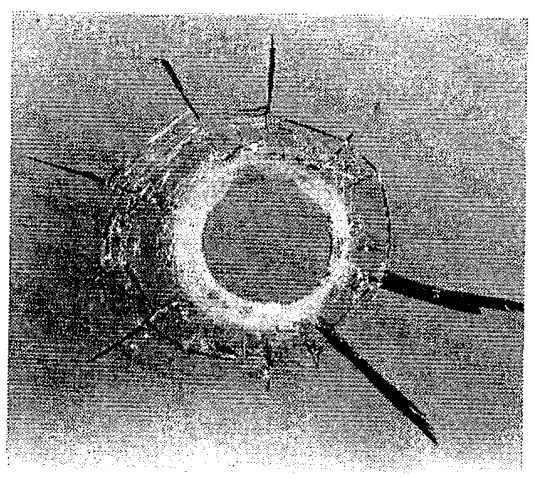

(d)

Fig. 13 Typical examples of punched holes 
(circular cracks and radial cracks are to be included). In order to express this measure $D_{\operatorname{mas}}$ relatively, the relative damaged length $L$ is defined as $L=$ $\left(D_{\text {max }}-d\right) / 2 t$. On the basis of $L$, punched holes are classified into the following four types.

(1) Evaluation $O$ : as shown in Fig. 13 (a), the tapered hole has no radial cracks, and few, even small, circular cracks. The relative damaged length $L$ is within the range $L<1$.

(2) Evaluation $\square$ : as shown in Fig. 13 (b),

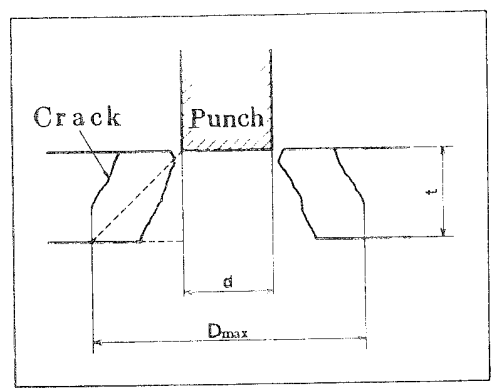

Fig. 14 Explanation of relative damaged length $L$ though there are some small circular cracks, there are no radial cracks. The relative damaged length $L$ is within the range $1 \leq L, 2$.

(3) Evaluation $\Delta$ : as shown in Fig. 13 (c), there are some small radial cracks which are apt to develop, as well as small circular cracks. The relative damaged length $L$ is within the range $1 \leq L<2$.

(4) Evaluation $x$ : as shown in Fig. 13 (d), there are some large radial cracks as well as circular cracks. The relative damaged length $L$ is within the range $2 \leqq L$.

\section{Punching Conditions}

The conditions to obtain good holes are shown in Fig. 15. Good holes can be obtained only in the region where $\bigcirc$ marks are given.

In order to obtain good holes, it is necessary that the pressure $p$ should be high and that the relative clearance $c / t$ should be within the range $0.3<c / t<0.7$, as shown in Fig. 15. A small relative clearance is apt to cause circular cracks and radial cracks. A large
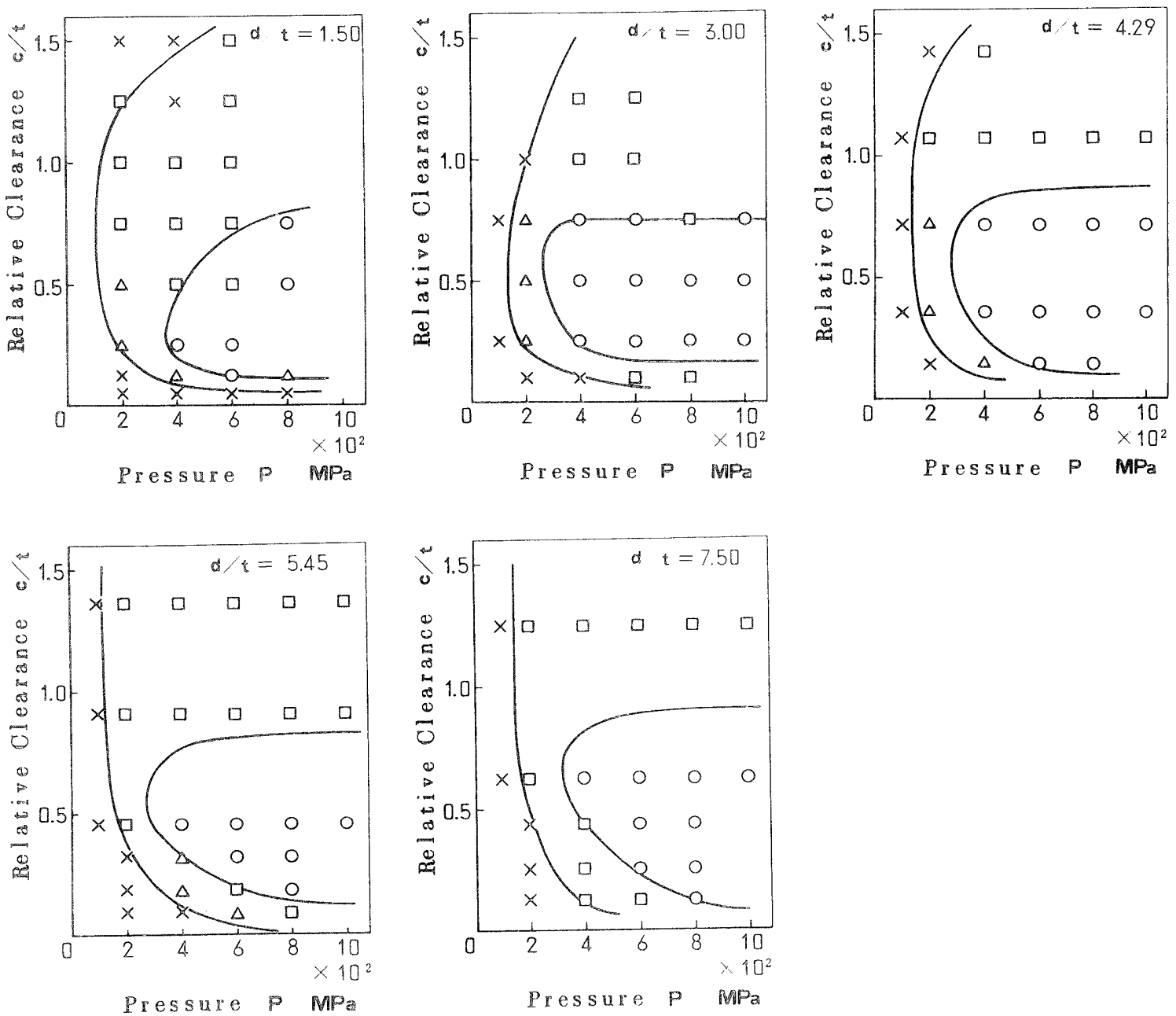

Fig. 15 Punching conditions to obtain good holes 
relative clearance tends to cause an excessively tapered hole.

It is presumed that punching becomes more and more difficult as the relative punch diameter $d / t$ decreases, because the relative depth of the hole increases in proportion to a decrease in the relative punch diameter. In Fig. 15, the region marked with $\bigcirc$ is small when $d / t$ is 1.50 . Therefore punching is supposed to be difficult under the condition $d / t<1$.

\section{Conclusions}

The main conclusions obtained in this research are as follows:

(1) It is possible to punch good holes in the sheet glass under the conditions $p \geqq 400 \mathrm{MPa}$, and $0.3<c / t<$ 0.7 .

(2) Too high pressure $p$ causes some defects near the rim of the sheet glass.

(3) Under the condition $d / t<1$, it is difficult to obtain good holes.

Although there is much left to be done in dealing with brittle materials, this research has brought forward the possibility of, and the necessary conditions for, punching holes in sheets made of brittle materials. We hope this will lead to the development of better and more varied methods for processing brittle materials. 